University of Nebraska - Lincoln

DigitalCommons@University of Nebraska - Lincoln

2005

\title{
A TRADE CONSTRUCTION KNOWLEDGE MODULE TO ENABLE USE OF DESIGN COMPONENT DATA IN PROJECT MANAGEMENT
}

\author{
Zhigang Shen \\ University of Nebraska - Lincoln, shen@unl.edu \\ Raja R. A. Issa \\ University of Florida, raymond-issa@ufl.edu \\ William J. O'Brien \\ University of Texas at Austin, wjob@mail.utexas.edu \\ Ian Flood \\ University of Florida, flood@ufl.edu
}

Follow this and additional works at: https://digitalcommons.unl.edu/constructionmgmt

Part of the Construction Engineering and Management Commons

Shen, Zhigang; Issa, Raja R. A.; O'Brien, William J.; and Flood, lan, "A TRADE CONSTRUCTION KNOWLEDGE MODULE TO ENABLE USE OF DESIGN COMPONENT DATA IN PROJECT MANAGEMENT" (2005). Papers in Construction Management. 10.

https://digitalcommons.unl.edu/constructionmgmt/10

This Article is brought to you for free and open access by the Construction Systems at DigitalCommons@University of Nebraska - Lincoln. It has been accepted for inclusion in Papers in Construction Management by an authorized administrator of DigitalCommons@University of Nebraska - Lincoln. 


\title{
A TRADE CONSTRUCTION KNOWLEDGE MODULE TO ENABLE USE OF DESIGN COMPONENT DATA IN PROJECT MANAGEMENT
}

\author{
Zhigang Shen', Raja R.A. Issa ${ }^{2}$, William O'Brien ${ }^{3}$ and Ian Flood ${ }^{4}$
}

\begin{abstract}
The complexity, tight budget, and dynamic market of today's construction project require the seamless integration of both design and construction data. However, despite the availability of both digital design tools (various CAD applications) and digital project management tools (such as schedule software and construction management software), design data has to still be entered manually into construction applications. In order to close this gap, CAD applications widely used in $\mathrm{AEC}$ industries are evolving toward providing the product data within the CAD package itself, in addition to the existing graphic-oriented data. While useful, those new data-driven CAD applications are largely design-oriented and are still hardly used directly in construction practices. In this research, a detailed case study is presented and analyzed to demonstrate the limitations of the current data-driven CAD application when used to support construction management. To address the limitations, a trade construction knowledge module using a specific product model is under development to provide domain views for different trades.
\end{abstract}

KEYWORDS: Construction Management; CAD data; Project Data Model, Product and Process Modeling; Multiple Trade Views; Visitor Pattern

\section{INTRODUCTION}

The complexity, tight budget, and dynamic market of today's construction project require seamless data communications between designers and Project Managers (PMs). However, despite we the availability of both digital design tools (various CAD applications) and digital project management tools (such as schedule software and construction management software), in the majority of current construction projects, PMs still have to manually read, store, and update design data in their construction applications.

The construction management process is very information and time sensitive. One primary information source for Project Managers (PMs) is design documents from

1 Ph.D. Student, Rinker, Sr. School of Building Construction, University of Florida, Rinker 304, Gainesville, FL 32611-5703, USA, 352/273-1152, zgshen@ufl.edu

2 Rinker Professor, M.E. Rinker, Sr. School of Building Construction, University of Florida, Rinker 304, Gainesville, FL 32611-5703, USA, 352/273-1152, raymond-issa@ufl.edu

3 Assistant Professor, CEPM Program, Department of Civil Engineering, University of Texas at Austin, 1 University Station C-1752, Austin, Texas 78712-0273,wjob@mail.utexas.edu

4 Holland Associate Professor, Rinker School of Building Construction, University of Florida, Gainesville, FL, 32611; PH (352) 273 1159; flood@ufl.edu 
designers. This data flow gap between design and construction causes significant disruption and delays of the construction projects. Typically, when PMs, estimators or even other architects want to retrieve design information, they might have to search dozens, if not hundreds of documents to find the scattered pieces of information and assemble them to produce the needed information. The information search and retrieval process could become extremely time-consuming, especially for large and complex projects (Pheng and Meng, 1997; Thomas et al., 1989). Furthermore, this manual retrieval process is error prone (Nambayashi et al., 2000) It has been estimated that up to $50 \%$ of all engineering changes in the manufacturing industry are corrections of errors rather than changed requirements or real improvements (Engelke, 1987). Considering the fragmented nature of the construction industry, the error rate is most likely higher than that in the manufacturing industry.

Since buildings are composed of many systems (architectural, structural, MEP, civil, etc.) any changes in one system may bring a sequence of corresponding changes to other systems. The chances for error will become even greater when changes are introduced to the original design as the burden to coordinate all the impacted projectparticipants falls onto the PMs' shoulders (See Figure 1).

If the current construction applications or design applications allow the PM to retrieve and analyze design data directly from the digital design documents, the chances for error and the burden to coordinate all impacted parties due to design changes will be reduced significantly.

To address the issue, some researchers have tried to add product database functions to the CAD programs by adopting standard product data models. Currently, CAD applications widely used in the AEC industry are evolving toward providing the semantic product data within the CAD package itself, in addition to the existing graphicoriented data. While useful, those new data-driven CAD applications are largely designoriented and are hardly used directly in construction practices.

There are two major obstacles that prevent contractors from directly using CAD data in construction management applications. The first one is data heterogeneity. Namely, there is no semantic consistency among CAD applications and construction applications (Eastman, 1999). The second obstacle is that the data-driven CAD itself lacks the mechanism to provide multiple trade views at various levels of detail. As illustrated in Figure 2, multiple views at various levels are crucial for effective project communication. Moreover, some trade views require domain knowledge that goes beyond the scope of the product data in the CAD application.
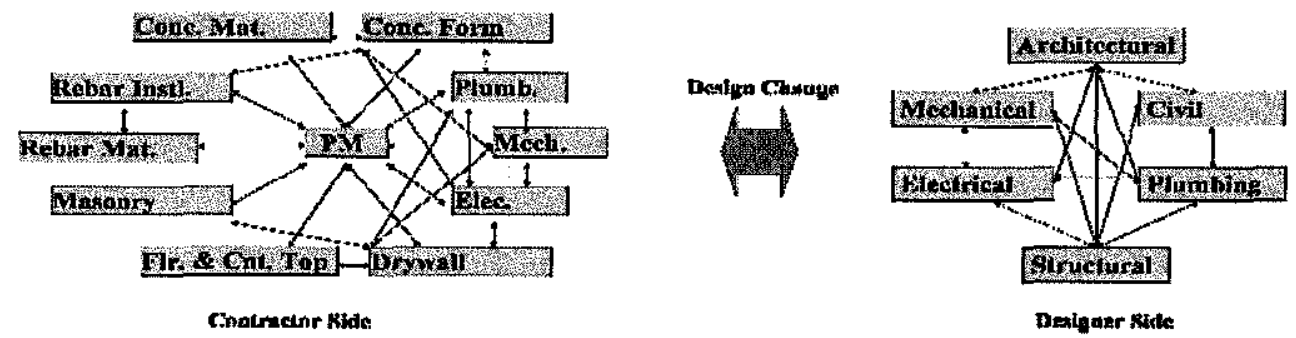

Figure 1. Design Changes and Burdens of Coordination on PM 


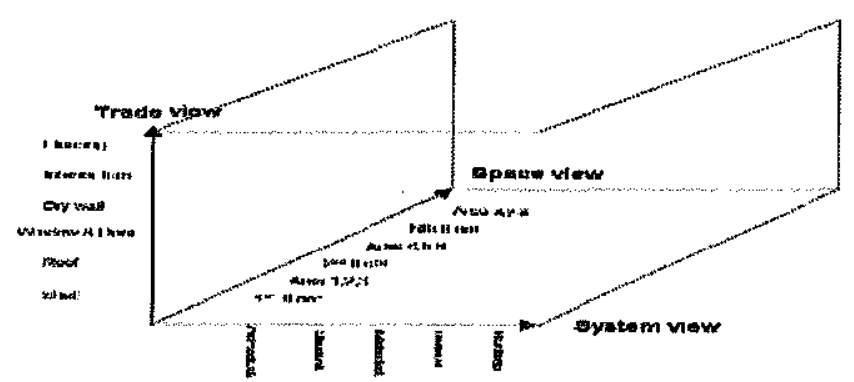

Figure 2. Multiple Views to a Construction Project

In order for contractors to electronically access and to analyze the product data, which resides in the CAD applications, a domain knowledge middleware is needed between the raw CAD product data and the construction-trade users' software. A case study is used to explain why such middleware is needed. Based on the case study the concept of a construction domain knowledge module will be proposed which will allow for different interpretation of CAD product data based on different domain needs.

There have been many research efforts trying to use CAD data directly to support construction operations such as project estimation (Staub-French and Fischer, 2003) or to support design alternate evaluation (Rivard and Fenves, 2000), or to support managing design changes (Wang and Soh, 2001). Several studies use Symbolic Model (or called Virtual Product Model by other people) (Clayton and Fischer, 1996) to organize the design data to facilitate the use of analyzing tools. The common features of these studies are: 1) a product model (or symbolic model) was created or used to represent and organize the design data; 2) analyzing module(s) was developed to analyze the existing design data. These studies also explored from different perspectives the methods of using design data directly to support other construction operations. In these studies, knowledge modules were developed to provide capabilities for analyzing design data from a particular trade perspective. They all have enhanced the understanding of the applications of the product data model in construction knowledge management. However, these studies have not fully addressed the problem of providing multiple trade views at various levels of detail.

\section{CASE STUDY}

Since estimating is a time-consuming task many tools were developed to help the estimator to get the job done quicker. These tools range from highlighter to digitizer, and to the latest CAD-based automatic estimating software.

Emerging CAD-based automatic estimating applications, such as AutoDesk Rivet, may be good for conceptual estimates, which do not need to incorporate detailed trade views. But they are not good enough for a detailed estimate since detailed estimation requires trade-knowledge from each trade's perspectives. There are several reasons for this statement: 1) CAD plans do not show every detail of the design. For example, architects generally do not draw nails, metal studs, paint layers, waterproof or wall ties, etc. on their blueprints. 2) Designers do not draw the construction methods either. The estimates of formwork and scaffolding etc., which are not part of the final building 
product, have to be derived from the domain experts' interpretation based on the design plan. 3) Furthermore, different trades often have different interpretations even from the same set of plans. 4) Building products are not only about design elements such as walls, roofs windows and doors, but also about spaces enclosed by those elements. However, the relationship between elements and spaces is often arbitrary. For example, in Figure 3, the estimator may be asked to find the floor area of the kitchen. In this case, the extent of the kitchen space depends on an individual's arbitrary definition.

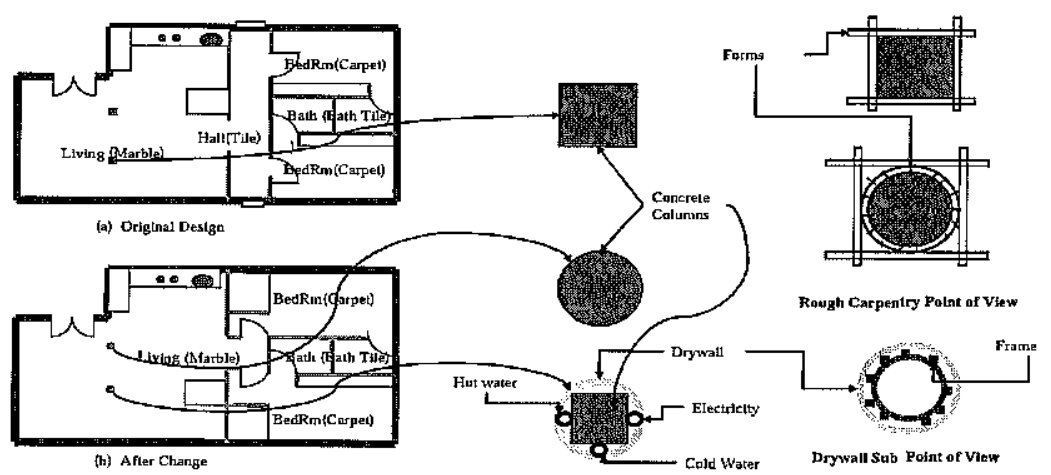

Figure 3. Original design and changed design

From the four observations listed above it can be concluded that CAD-based automatic estimates are not enough for detailed estimates. It is obvious that user intervention and interpretation are needed to make any CAD-based automatic estimate to work well, regardless of whether the design documents are in 2D, 3D or 4D.The design changes shown in Figure 3 are used to further support this conclusion. The two square columns were changed to two round ones and one column needs to be reduced in size to incorporate the MEP pipes and conduit. To simplify this case, only the views required by the drywall subcontractor, the concrete supplier and the rough carpentry subcontractor will be considered. The impact of these design changes on each of them are:

1) For the concrete supplier the change is just a simple quantity change. The change in volume of concrete needed for the columns. 2) For the rough carpentry subcontractor the change means more labor and more complicated formwork is needed. Not only does he/she need to calculate the change in surface area but they also need to find out the diameter of the round column and translate it into labor hours, additional duration and special formworks. Regarding geometric information, both the surface area of the column and the shape description of the section of the columns are needed.

3) For the drywall subcontractor, things are a little more complicated: not only does the contractor need to know the geometry features of the round column, which is shown in the architectural plan, but also the size of the inner concrete square column which is shown on the structural plan and the position and size of the MEP pipes and conduit which are shown on the MEP plans will be needed. The estimator or PM needs to collect all these design data and translate them into quantity estimates for the metal frame, the 
curved drywall and the corresponding labor and duration. Finally the PM has to assemble all the estimates together to have a lump-sum price for these column changes. In practice, the drywall contractor will also need to add overhead cost due to the schedule change to the estimates, since the drywall contractor cannot wrap the column until all the MEP installation, inspection and insulation are done.

Table 1 shows a summary of the data needed by subcontractors to evaluate the changes shown in Figure 3. Through the traditional manual approaches we can always get the cost impact of the changes by re-estimating, recalculating, and updating several dozens (in the case of minor changes) of estimate, schedule and design documents. But this method is very time-consuming and error-prone. As stated earlier, CAD-based estimating is not able to handle this situation without the user's intervention and direction. In the above mentioned drywall case, estimate of the overhead cost due to the schedule change is very difficult for CAD-based computer estimates, because there are many condition-sensitive variables associate with the cost.

In summary, this case study presents a very common, simple case of design change. Both traditional manual estimating approaches and CAD-based automatic approaches are not good at handling this situation. The conclusion from this case study is that in order to have advantages of both the speed of automation method and the flexibility of manual method, a compromise between the two has to be found.

\section{RESEARCH GOAL}

The goal of this research is to develop a construction information model to integrate design and schedule data to support dynamic multiple views from various trade perspectives at various levels of detail. One potential application of the model is to support accurate cost and resource loading to improve and extend CPM functionality (e.g just-in-time material management.

Table 1. Case Study of Subcontractor Information

\begin{tabular}{|l|c|c|c|c|}
\hline \multicolumn{1}{|c|}{ Need Following Data } & $\begin{array}{c}\text { Concrete } \\
\text { Trade }\end{array}$ & $\begin{array}{c}\text { Rough Carpentry } \\
\text { Trade }\end{array}$ & Drywall Trade & Remarks \\
\hline Architectural Data & No & NO & $\begin{array}{c}\text { Yes (Geom. \& } \\
\text { Material Data) }\end{array}$ & \\
\hline Structural Data & Yes & $\begin{array}{c}\text { Yes (Geometry } \\
\text { Data) }\end{array}$ & $\begin{array}{c}\text { Yes (Geometry } \\
\text { Data) }\end{array}$ & \\
\hline MEP Data & NO & NO & $\begin{array}{c}\text { Yes } \\
\text { (Geometrical } \\
\text { Data) }\end{array}$ & \\
\hline Schedule Data & NO & NO & YES & \\
\hline Domain Rationale & NO & YES & YES & \\
\hline $\begin{array}{l}\text { Does the Manual } \\
\text { Approach Work? }\end{array}$ & YES & YES & YES & Too \\
\hline $\begin{array}{l}\text { Does the CAD-Based } \\
\text { Approach Work? }\end{array}$ & YES & NO & NO & \\
\hline
\end{tabular}


The expected research contribution of the model is that it provides an example of construction knowledge management using the Configurable Environment $(\mathrm{CE})$ concept (O'Brien et al. 2004) to develop construction product / process model. CE encourages software users' intervention and the customization of an automatic information processing system to achieve the combination of the flexibility of human reasoning and the productivity of machine's mass-data processing. The study explores a methodology to use knowledge representation of construction and Object-Oriented programming in addressing the dynamic nature of construction information. The scope of this research is limited to providing the fundamental methodology and implementing of a prototype of the proposed system for validation purposes.

\section{PROPOSED MODEL}

\section{GENERAL DESCRIPTION}

Existing CAD and database technology (McAuley 2000) provide a basis for creating a semi-automatic application, which will allow for automatical reading of the design documents (assume semantic data consistency) and schedule data into a project database that will allow the user to define their views and queries. Thus, both flexibility and automation will be possible when processing project information. The proposed data model is shown in Figures 4.

Figure 4 shows schematically the overall picture of the proposed system. For research purposes, it is assumed that the geometry, material property and schedule data have already been read into the system. Figure 4 also conceptually shows how the components of the proposed model work together. Behind the user interface there is an application called Visitor, which could be configured to generate views specified by the users. This will allow flexible views to be created based on the different interpretations of the common data sets. This is exactly how the traditional manual approach works. However this semi-automatic approach based on the proposed model will be much faster especially when handling changes because the design objects data have been well organized.

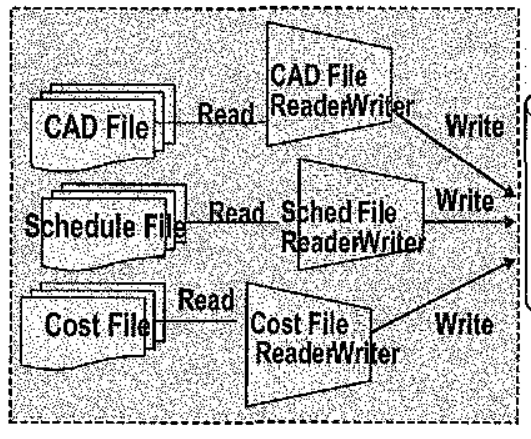

Existing System

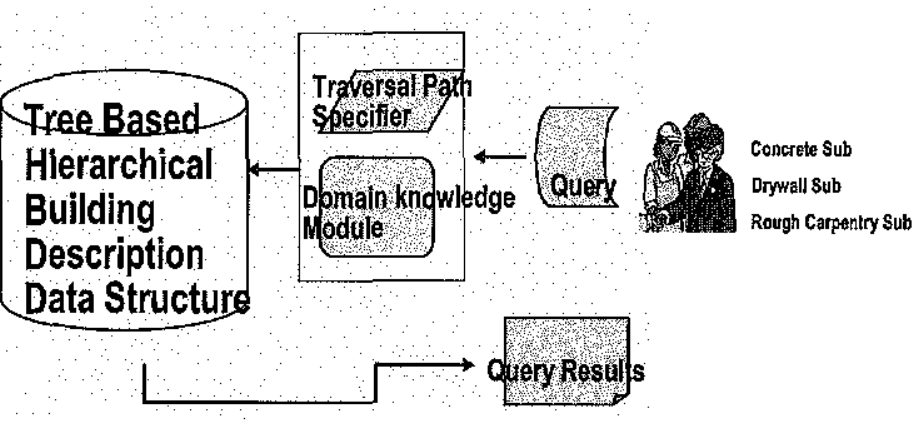

Proposed System

Figure 4. Conceptual Model 
The tree structured project database shown in Figure 5 will provide data about geometry, material, assembly and schedule information for the design objects such as walls, columns, windows etc. The contents of the tree do not reflect special domain rationale and knowledge. It may be called a product description tree from the contractor's point of view.

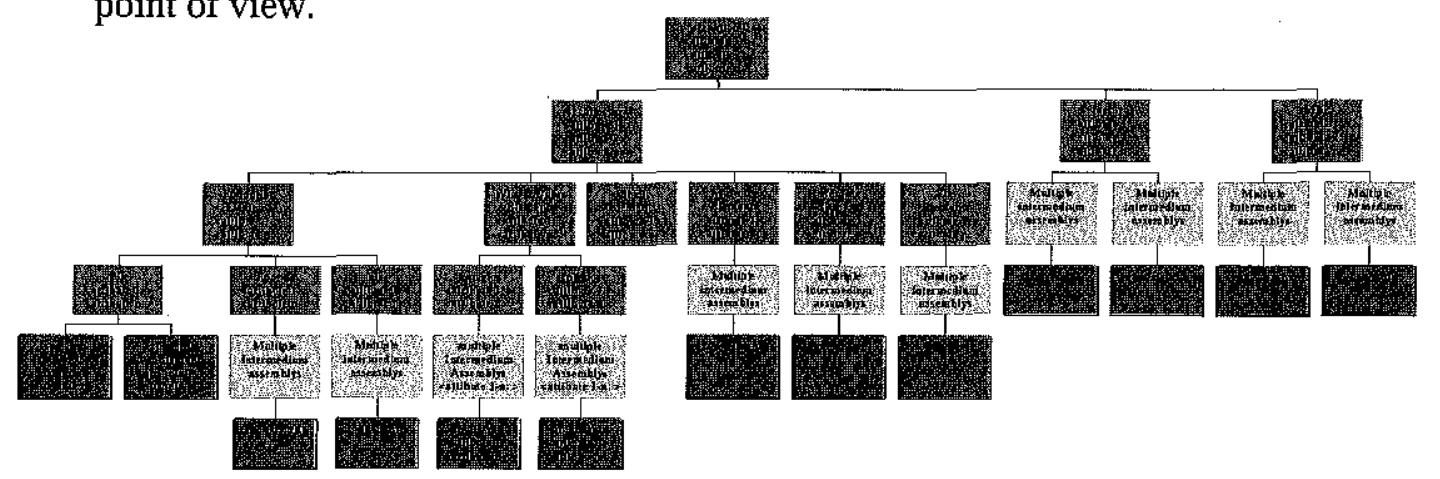

Figure 5. Model Data Structure

Figure 6 showswhat properties are in the model data structure and how they are organized. The appropriateness of this data structure is based on two observations: 1) it is not necessary to share all domain knowledge among all participants; typically, the information that needs to be shared among participants is only a small portion of the design data. For example, estimators do not need to know the structural load on a floor or beam in order to develop the estimate nor do they need to know how the architect organized the functional spaces. From contractor's perspective, the interested data are geometry, specifications and schedule. 2) Despite the uniqueness and changing nature of construction projects, the data structure of their functional components remains stable. This allows us to partition them into stabled hierarchical categories. The similar idea can be found in other database systems (Aguilera et al. 2002).

The proposed data tree contains building product data (include 3D geometry and material data) and schedule data. The domain knowledge module includes a traversal path specifier and path algorithm. This module specifies what domain views are generated and at what detail levels through a user interface (See Figure 6). The level of details that this model can provide is constrained by the minimum unit in the data model.

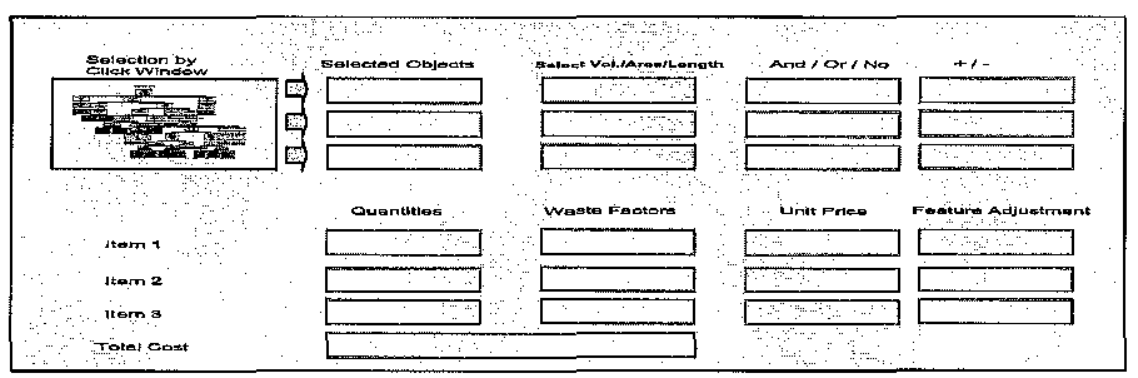

Figure 6. Proposed User Interface 


\section{Examples of Visitor Pattern Procedure}

The previous case study in Figure 3, in which the two square columns are changed to two round ones, is used to illustrate how the visitors generate views.For the concrete supplier to determine a new estimate, the concrete visitor will only need to visit the structural part of the tree and put together the new volume numbers of the two new columns. The overall process involves identifying which columns to visit and which column values need to be retrieved and then to add them together (Simple Algorithm). This simple geometric property retrieval may be done automatically without too many user interventions.

Similar to the concrete visitor, the rough carpentry visitor need to visit the structural part of the tree. However, the carpentry visitor will need to retrieve more data about the geometrical properties of the two new columns. Two separate surface areas and the diameter of the round concrete column are needed to apply different algorithms to each shape to calculate the formwork. Depending on the user specifications, the calculated results may be listed separately or in a summary format. This process actually involves the rough carpenter's domain knowledge: how to design the formwork for square columns and for the round ones. This knowledge will be reflected in the algorithm for how to calculate the formwork quantities, since formwork design is not shown on any design documents. The estimate is solely based on the rough carpenter's interpretations of the existing structural data sets. CAD-based estimates are not able to handle this case because of the lack of domain rationales.

The drywall subs are in a similar situation as the rough carpenters except that their visitor will need to visit more documents, not only the structural parts but also the architectural, and MEP parts. Since the design change result in schedule changes schedule properties will also need to be retrieved from the data tree.

Figure 7 sketches a preliminary implementation of this system prototype using Object Oriented UML diagram.

\section{SUMMARY}

The difficulty of the timely retrieval of useful information, which includes multiple views of the same data set, from data sources related to the design, the schedule and subcontractors, is one of the major causes that lead to low productivity in the construction industry. The case study presented in this paper demonstrates that currently either traditional manual method or CAD based automatic method along is not able solve the problem. To improve the performance of information retrieval by multiple trades, a semiautomatic approach is proposed. This research is currently developing a construction domain knowledge system, which allows for multiple views to be generated from same data set by applying the Visitor Pattern in Object Oriented Programming. 


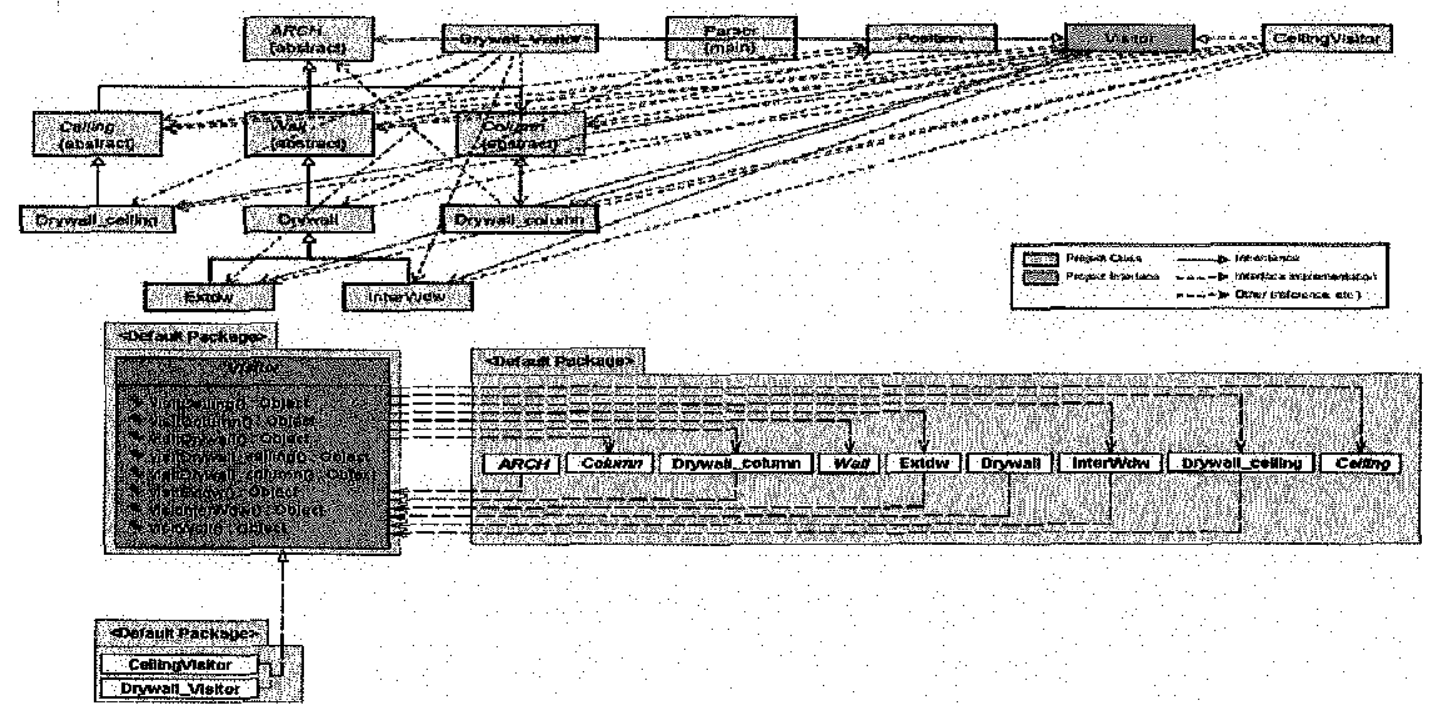

Figure 7. Partial UML Diagram of the Prototype

\section{REFERENCES}

Aguilera, V., Cluet, S., Milo T., Veltri, P., Vodislav, D., "Views in a Large Scale XML Repository", the VLDB Journal, 11(3), pp. 238-255, 2002.

Clayton, M.J., Fisher M., Teicholz, P. and Kunz J., "Rapid conceptual design evaluation using a virtual product model", Engineering Applications of Artificial Intelligence, 9(4), pp.439-451, Elsevier Science, NY, 1996.

Engelke, W.D., How to integrate CAD/CAM Systems, Marcel Dekker, NY, 1987.

McAuley, C., Programming AutoCAD in ObjectARX, Autodesk Press, 2000.

Nambayashi, K., Shiino, J., Ohtomo, T., Uchiiyama, Y., and Nagayasu, O., "An Actual State And A Prospect Of Computer And Network Application For Transferring And Sharing Information Among Participants Of Building Construction Viewing From The Job Site In Japan", Proceedings of the Eighth International Conference (ICCBE-VIII), Computing in Civil and Building Engineering, Stanford University, CA, August 14-17, pp. 138-153, 2000.

O'Brien, W., Issa R., Shen, Z., and Xie, H. (2004, in press). "Configurable environments: a vision for future project information technologies" in Kazi, S. (ed.) Knowledge Management in the Construction Industry: A Socio-technical Perspective, Idea Group Publishing, Hershey, PA 17033, USA, 339-358.

Pheng, L.S. and Meng, C.Y., Managing Productivity in Construction: JIT Operation and Managements, Ashgate Publishing, Brookfield, Vermont, 1997.

Rivard, H. and Fenves, S.J., "A representation for conceptual design of buildings", Journal Of Computing In Civil Engineering, ASCE, Reston, VA, 14(3), pp. 151$159,2000$. 
Staub -French, S. and Fisher, M., "A feature ontology to support construction cost estiamting", Artificial Intellegence for Engineering Design Analysis and Manufacturing, Cambridge University Press, 17, pp.133-154, 2003.

Thomas, H.R., Sanvido, V.E., and Sanders, S.R., "Impact of Material Management on Productivity", Journal of Construction Engineering and Management, ASCE, Reston, VA, 115(3), pp. 370-384, 1989.

Wang, Z., and Soh C. K., "Managing Design Changes For Multiview Models", Journal Of Computing In Civil Engineering, ASCE, Reston, VA, 15(2), pp. 102$111,2001$. 